\title{
Preliminary experience with a hospital blood pressure follow up clinic with nurse practitioner assessment and microprocessor based data retrieval
}

\author{
P C RUBIN, JOAN L CURZIO, ANDREW KELMAN, HENRY L ELLIOTT, JOHN L REID
}

\begin{abstract}
Experience over two years with 376 hypertensive patients managed at a clinic where the primary observations are made by a trained nurse, clinical information is held on a microprocessor, and treatment follows a standard stepped care approach has been assessed. Blood pressure control after both one and two years was appreciably improved, with over $70 \%$ of patients having diastolic pressure below $90 \mathrm{~mm} \mathrm{Hg}$ compared with $22 \%$ of patients when they first attended the new clinic. The nonattendance rate was half that of the conventional hospital outpatient clinic.

A computer based record system with a nurse run hypertension clinic is acceptable to patients and offers the possibility of more effective long term control of blood pressure in large numbers of patients.
\end{abstract}

\footnotetext{
University Department of Materia Medica, Stobhill General Hospital, Glasgow G21 3UW

PETER C RUBIN, DM, MRCP, Wellcome Trust senior fellow in clinical science

JOAN L CURZIO, MSC, RGN, research nurse

ANDREW KELMAN, PHD, principal physicist

HENRY L ELLIOTT, MD, MRCP, lecturer

JOHN L REID, DM, FRCP, regius professor of materia medica

Correspondence to: Professor J L Reid.
}

\section{Introduction}

Hypertension affects between $10^{\circ}{ }_{0}$ and $20^{\circ}{ }_{0}$ of the adult population in this country ${ }^{1}$ and is a leading cause of cardiovascular morbidity and mortality. ${ }^{2-4}$ There is increasing evidence that even in the more modest grades of hypertension lowering blood pressure can reduce both disability and death. ${ }^{5-8}$ The effective long term management of hypertension therefore presents a major opportunity for preventive medicine. Nevertheless, providing this care requires that large numbers of asymptomatic people must be followed over long periods of time with assessment of blood pressure control and encouragement to comply with drug therapy.

Conventional approaches to patient care in both general and hospital practice do not readily lend themselves to the large scale, long term problems presented by hypertension. ${ }^{9-14}$ We describe here our preliminary experience with a blood pressure follow up clinic which uses developments in microcomputer technology and paramedical help to overcome some of these problems. So far the system has been used in hospital but we believe it might as easily be applied in general practice, health centres, or industrial sites.

\section{Clinic structure}

Several aspects of the blood pressure follow up clinic differ substantially from the conventional hospital clinic. Firstly, to accommodate large numbers of patients yet allow adequate time for consultation and scope for flexibility in appointments, the clinic operates throughout the week (at present on four half days per week, with scope for expansion when necessary). Secondly, the person responsible for the routine measurement of blood pressure and patient evaluation is a nurse practitioner. ${ }^{15}$ Thirdly, patient information is stored in a readily accessible manner on a microprocessor. Finally, a uniform therapeutic 
policy has been adopted based on the stepped care approach, as discussed below.

The initial assessment of patients referred by local general practitioners for evaluation and management of hypertension is undertaken by a senior physician at a conventional hospital outpatient clinic. When appropriate investigations have been performed and a management regimen has been established patients are transferred to the new follow up clinic. At this time a simple two page computer input form is completed. Details of the computer program have been published elsewhere. ${ }^{16}$ Briefly, complete details of the patient's cardiovascular risk profile, clinical features, and laboratory indices are stored in a permanent data file, which is updated at least once each year. A subroutine enables clinically important information (for example, target blood pressure and risk factor status) to be extracted from this permanent file and printed out at each clinic attendance. ${ }^{15}$

At each clinic visit a brief general history relating to cardiovascular risk factors and drug treatment is taken by the nurse practitioner, who then records the blood pressure using a semiautomated sphygmomanometer (Sentron, Bard Biomedical, Lombard, Illinois, USA). Provided the blood pressure is within the target range, cardiovascular risk profiles such as smoking and obesity are being appropriately addressed, and general health appears to be good, then the patient would not see the doctor at that visit. When a patient is overweight or smokes then these problems are assessed by the nurse practitioner and if possible modified with the help of medical staff and paramedical services such as dietitians. There are two circumstances in which a patient is reviewed by a doctor. The first is at the request of either the nurse or the patient as a result of the blood pressure being above target, a suspected drug side effect, or a new clinical problem or symptom. The second is that every patient has an annual medical examination conducted by a doctor and comprising a physical examination, an electrocardiogram, determination of biochemical and haematological indices, and urine analysis.

\section{Preliminary results}

A total of 247 patients were transferred from existing hospital follow up to the clinic during its first year of operation and a further 129 new patients during the second year. Over $85^{\circ}$ of patients had essential hypertension and they ranged in age from 18 to 80 .

Patients have been managed according to a standardised regimen. We begin by assessing cardiovascular risk factors such as obesity and smoking and try to improve the profile by non-drug means. This is reflected by the fact that $17^{\circ}$ of patients attending the clinic at present are having no drug treatment (see below). When other risk factor modification has been tried and a further fall in blood pressure is required then treatment is begun with a $\beta$ blocker. If the target blood pressure is still not achieved then a thiazide diuretic is added. Those patients who still do not respond are subsequently treated with a third drug: a vasodilator (hydralazine), a calcium antagonist (nifedipine), or an $\alpha$ blocker (prazosin).

This sequence of initial risk factor modification followed by stepwise introduction of drug treatment has been followed in $81^{\circ}$, of the people attending the clinic: at the end of the second year of the clinic $17^{\circ}$; of patients were receiving no drugs, $19^{\circ}{ }_{\mathrm{o}}$ a $\beta$ blocker alone, $27 \%$ a $\beta$ blocker and diuretic, and $18 \%$ a $\beta$ blocker, diuretic, and vasodilator. Variation from this sequence of drug treatment arises when there is a contraindication to one of the drugs or the development of an adverse reaction. Thus the remaining $19^{\circ}{ }_{0}$ of patients were receiving treatment such as diuretics alone and $\beta$ blockers plus vasodilators

In 1982-3, the average rate of non-attendance of follow up patients for the medical outpatient clinics at Stobhill Hospital was $19^{\circ} \%$, while the average throughout this year at the new blood pressure follow up clinic was only $10^{\circ}{ }_{0}$. Sixty three patients did not have a current appointment at the end of the second year. Nineteen of these had been transferred for administrative reasons to other clinics and 10 had died. Twelve patients asked to attend only their general practitioner and six had left the area. Sixteen patients $\left(4^{\circ}{ }_{0}\right)$ failed to attend on three consecutive occasions and no further appointments were sent.

The distribution of blood pressure in patients on their initial referral to the assessment clinic is shown in the table. Although they had been attending a medical outpatient clinic for management of hypertension for between two months and 10 years, most patients had poorly controlled blood pressure and only a minority had satisfactory control with treatment. After adjustments to the treatment regimen these patients were then transferred to the follow up clinic. The distribution of blood pressure at the end of the first and second year is also shown in the table. Most patients have achieved and maintained a blood pressure below $150 / 90 \mathrm{~mm} \mathrm{Hg}$, and when age differences in target blood pressure are taken into account over $70^{\circ}$ of patients attending the follow up clinic had well controlled blood pressure at the end of the second year of the clinic. Supine blood pressures of patients when first seen at the
attendance clinic and after one and two years at the follow up clinic. Results are percentages of patients

\begin{tabular}{cccc}
\hline Blood pressure & Initial & After 1 year & After 2 years \\
\hline Systolic & & & \\
$\leq 150$ & 28 & 61 & 59 \\
-180 & 35 & 29 & 33 \\
$>180$ & 37 & 9 & 7 \\
Diastolic & & & \\
$\leq 150$ & 22 & 70 & 71 \\
-180 & 54 & 27 & 26 \\
$>180$ & 25 & 3 & 2 \\
\hline
\end{tabular}

\section{Discussion}

These preliminary results suggest that this new style blood pressure follow up clinic is both acceptable to most patients, as indicated by the improved attendance rates, and achieves a high percentage of success in maintaining good blood pressure control. They also show that a standardised stepped care approach may be successfully applied to the management of hypertension under clinical practice conditions with a large group of patients.

We believe that this approach to the long term management of hypertension offers substantial advantages over the conventional follow up in hospital and general practice and has broad implications for the control of hypertension in the community. A high degree of patient acceptability is coupled with the concentration of medical skill on those patients who require the advice of a doctor. The selective printout of relevant clinical information from the microprocessor readily identifies the primary issues in the management of each individual patient. At present over 400 patients are being supervised at relatively modest cost in terms of staff resources. The present staff could manage 700-900 patients. Detailed comparisons of total costs of this approach with conventional care in hospital and general practice are being undertaken.

There is considerable evidence in both Britain and North America that hypertension in the community is both underdiagnosed and undertreated. The increasing awareness both of the importance of hypertension as a predictor of subsequent morbidity and of the value of treatment is likely to increase progressively the number of patients receiving treatment for hypertension. ${ }^{1718}$ Since a substantial proportion of these patients are likely to be easily controlled and require only infrequent medical review it seems very probable that the clinic structure which we are evaluating - that is, run by a nurse and based on a microprocessor-might find wide application not only in hospitals but also in health centres or at places of work.

The establishment of this clinic was made possible by a grant from the Scottish Chest, Heart, and Stroke Association and support of the Northern District of the Greater Glasgow Health Board. We thank

Mrs J Richardson and Mrs J Hamilton for clerical and secretarial help and clinical colleagues who have referred patients to the clinic.

\section{References}

1 Hawthorne VM, Greaves DA, Beevers DG. Blood pressure in a Scottish town.

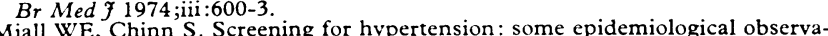
tions. Br Med F 1974; iii :595-600.

Kannel WB, Wolf PA, Verter J, McNamara PM. Epidemiologic assessment of the role of blood pressure in stroke. $\mathcal{F} A M A$ 1970;214:301-10

Kannel WB, Castelli WP, et al. Role of blood pressure in the development of congestive heart failure. $N$ Engl $\mathcal{F}$ Med 1972;287:781-7.

Veterans Administration Cooperative Study Group. Effects of treatment on morbidity in hypertension II. Results in patients with diastolic blood pressure averaging 90 through $114 \mathrm{~mm} \mathrm{Hg.} \mathrm{FAMA} \mathrm{1970;213:1143-52.}$ 6 Medical Research Council Working Party on Mild to Moderate Hypertension. pilot trial. Br Med $\mathcal{f} 1977 ; 1$ :1437-40. 
7 Hypertension Detection and Follow-up Program Cooperative Group. Five-year findings of the hypertension section and follow-up program 1. Reduction in mortality of persons with

8 Management Committee. The Australian therapeutic trial in mild hypertension. Lancet 1980;i:1261-7.

Bulpitt CJ, Daymond MJ, Dollery CT. Community care compared with hospital outpatient care for hypertensive patients. $\mathrm{Br} \mathrm{Med} \mathcal{F} 1982 ; \mathbf{2 8 4}: 554-6$.

$10 \mathrm{Hart} \mathrm{JT}$. The management of high blood pressure in general practice. $f \mathrm{R}$ Coll Gen Pract 1975;25:160-92.

11 Heller RF, Rose G. Current management of hypertension in general practice. Br Med' $f$ 1977; i: 1442-3

12 Ritchie LD, Currie AM. Blood pressure recording by general practitioners in north-east Scotland. Br Med f 1983;286:107-9.
13 Heller RF, Rose G. Current management of hypertension in hospital. Br Med $\mathcal{f}$ 1977; : 1441-2.

14 Beilin LJ, Bulpitt CJ, Coles EC, et al. Long-term antihypertensive drug treatment and blood pressure control in three hospital hypertension clinics. $\mathrm{Br} H$ eart $f$ $1980 ; 43: 74-9$.

15 Curzio J. Monitoring hypertension. Nursing Times 1983;559-61.

16 Kelman A, Reid JL, Rubin PC. BP: A microcomputer program for use in a hypertension clinic. Computer Programs in Biomedicine 1982;14:185-90.

17 Coope J. Hypertension in general practice: what is to be done? $\mathrm{Br}$ Med $\mathcal{F} 1984$ 288:880-1.

18 Memorandum from a WHO/ISH meeting. Guidelines for treatment of mild hypertension $1983 ; 5: 395-7$.

(Accepted 15 fune 1984)

\title{
Motor neurone disease: can we do better? A study of 42 patients
}

\author{
P G NEWRICK, R LANGTON-HEWER
}

\begin{abstract}
A feeling that patients with motor neurone disease were not always well managed prompted a study of the symptoms, functional levels, and use of aids in a group of 42 patients. Pain, falls, constipation, and swelling of the legs emerged as the major symptomatic problems. At the time of assessment two thirds of the patients appeared to be in need of aids which had not been provided. Disturbance of sleep secondary to positional nocturnal discomfort caused much distress to both the patient and spouse; and this might be eased by the use of an electric turning bed. Over half the patients said that they disliked attending neurology outpatient clinics. Criticism centred on poor transport arrangements, lack of information about the control of symptoms, and unsatisfactory help from junior staff. A key worker should be identified as part of a new strategy for managing these patients.
\end{abstract}

\section{Introduction}

"He is no more use to me than the milkman." The writer was a patient with motor neurone disease who almost certainly did not intend to belittle the important role of the milkman in our society but who felt that his neurologist could have been more helpful. His statement and our experience prompted us to a closer examination of symptoms and practical problems in motor neurone disease. There are several reviews of management of motor neurone disease ${ }^{-6}$ and articles on specific aspects such as cricopharyngeal myotomy, ${ }^{7}$ palatal prostheses, ${ }^{8}$ and ventilator care. ${ }^{9}$ None of the published work, however, gives clear guidance about the frequency and management of common symptoms and practical problems. We designed our study to provide factual information which might form the basis for an improved pattern of care.

Department of Neurology, Frenchay Hospital, Bristol BS16 1LE P G NEWRICK, MB, MRCP, medical registrar

R LANGTON-HEWER, MB, FRCP, consultant neurologist

Correspondence to: Dr R Langton-Hewer.

\section{Patients and methods}

Forty five patients with a definite diagnosis of motor neurone disease were identified from the diagnostic indices of three consultant neurologists in two units (30 from the Department of Neurology, Bristol were under the care of R L-H and 15 were from the Wessex Neurological Unit, Southampton). A letter was initially written to the patient asking if he would be willing to be interviewed by a doctor who had a particular interest in his condition. One of us (PGN) conducted a single interview with 42 of the patients (two patients had died before being seen and in one case the general practitioner felt that his patient should not be approached). Twenty five were interviewed in their homes with the spouse and the remainder in various hospital departments. Two were inpatients at the time of interview.

The interview was conducted in an open unhurried fashion with the objective of trying to allow problems to emerge readily. It was unstructured in that the wording of the questions was not specified. Nevertheless, the interviewer did have a checklist, which was not visible to the patient. Specific questions were asked, to assess the following:

Duration of symptoms and interval before diagnosis

Duration of independence or otherwise-We accepted the views of patients and their families on the duration of independence and did not seek to categorise them by an interpretation of their problems.

Disability-Disability was assessed on performance in three aspects, with a new scale. A new scoring system is justified because there are no scales designed specifically for use in motor neurone disease. Of the numerous indices of activities of daily living, ${ }^{10}$ most of the existing scales relate to cerebrovascular disease, do not include bulbar disability, and are time consuming in practical use. Functional staging in motor neurone disease $\mathrm{e}^{5}$ does not allow for the variation in severity between bulbar and limb disorder in the same patient. A scale for dysarthria and bulbar problems requires special skills in use. ${ }^{11}$ With our scale bulbar function, limb function, and sources of patient care were scored out of a total of 25 points (see Appendix). The normal person would score 25 . Bulbar function (max score 7 ) was assessed on swallowing, drooling, and speech. Arm function (max score 7) was largely concerned with self care and was scored on ability to dress, bath, and manage to use the lavatory. Leg function (max score 8) was assessed on the different aspects of mobility: walking, managing stairs, and transfer from a bed to a chair. Arm and leg function were linked together as a total limb score (max score 15). The sources of patient care were recorded (max score 3 ) because this is a guide to overall function-for example, whether the patient coped with help from the family alone or relied on outside help or regular holiday relief. The scale is not designed to bring out the element of time and effort the disabled person must expend in comparison with normal but rather to delineate severe from moderate or mild disability. 